\title{
Ronald G. Beckett and Gerald J. Conlogue: Paleoimaging: field applications for cultural remains and artifacts
}

\author{
CRC Press, 2010, pp 405, Hardback ISBN 978-1-4200-9071-0
}

\author{
Jason M. Wiersema
}

Published online: 4 December 2010

(C) Springer Science+Business Media, LLC 2010

The book entitled Paleoimaging: Field Applications for Cultural Remains and Artifacts represents a valuable reference for the subset of archaeologists and curators whose research is heavily influenced by the constraints associated with the collection and analysis of fragile mummified remains. Practitioners in search of a detailed, well informed review of the available technologies and their relative advantages and disadvantages will benefit from this book during the project design and funding processes. However, there are few references to contexts that are more generally applicable, thereby potentially limiting the audience that would apply the techniques in the specific manner described. On the other hand both the detail and real world examples presented in the book encourage consideration of the possible applications of these technologies in other field contexts. In other words, the book is focused on mummies as the primary context in which these technologies have been applied, but others, including bioarchaeologists and forensic anthropologists may benefit in ways not specifically described in the text. There are undoubtedly less traditional uses for these technologies for those whose material falls on the opposite side of the taphonomic spectrum from the well preserved mummies used as examples in this text. Recording the location of human remains in relation to surrounding matrix in cases of poor preservation, tissue damage, or commingling is an example.

The book also presents an unapologetic opinion of what the authors feel is necessary with regard to the personnel needed to effectively employ these techniques. The authors suggest that the inclusion of experts in the use and interpretation of the described techniques is critical to the successful use of the equipment. This will likely be considered impractical by some, but again the book is useful in this regard as a well informed reference to those who do, or plan to do this kind of investigation. The format of the book is effective and the level of detail will be useful to principal investigators who are in the process of project design and funding acquisition. However, the audience may be limited by the examples presented by the authors.

J. M. Wiersema $(\bowtie)$

Forensic Anthropologist, Harris County Institute of Forensic

Sciences, Houston, TX, USA

e-mail: jason.wiersema@ifs.hctx.net 